\title{
A social work study on measuring the effects of social cognitive consultation on welfare receivers' entrepreneurship attitudes and behavior
}

\author{
Najmeh Sedrpoushan $^{\mathrm{a}^{*}}$, Mohammad Reza Iravani ${ }^{\mathrm{b}}$ and Narges Khatoon Mansourzadeh ${ }^{\mathrm{b}}$
}

${ }^{a}$ Counselling Department, Islamic Azad University, Science and Research Branch, Tehran,14778 93855, Tehran, Iran

${ }^{b}$ Department of Social Work, Islamic Azad University of Khomeinishahr, Khomeinishahr Branch, Daneshjou Blvd, Iran

\begin{tabular}{|c|c|}
\hline A R T I C L E I N F O & A B S T R A C T \\
\hline $\begin{array}{l}\text { Article history: } \\
\text { Received December 15, } 2011 \\
\text { Received in Revised form } \\
\text { February, 14, } 2011 \\
\text { Accepted 24 March } 2012 \\
\text { Available online } \\
\text { March } 272012 \\
\text { Keywords: } \\
\text { Entrepreneurship's perception } \\
\text { Social cognitive consultation } \\
\text { Welfare recinients }\end{array}$ & $\begin{array}{l}\text { One of the most important responsibilities of welfare receivers in all communities is to find a } \\
\text { job. In many cases, people are encouraged to act as entrepreneurs and create jobs and } \\
\text { opportunities. In this study, we perform an empirical study among } 280 \text { welfare receivers to } \\
\text { measure the effects of social cognitive consultation on changing receivers' entrepreneurship } \\
\text { attitudes. The study uses Bandura's social cognitive questionnaire and select } 30 \text { volunteers who } \\
\text { receive the lowest marks in this survey and they are divided into two groups. The study } \\
\text { provides a consultation among them for eight consecutive sessions of two hour-period and the } \\
\text { results indicate that the consultation can change both welfare receivers' perception and their } \\
\text { attitude, significantly. }\end{array}$ \\
\hline
\end{tabular}

(c) 2012 Growing Science Ltd. All rights reserved.

\section{Introduction}

During the past few decades, there have been substantial changes on world's economy. Every year, many people may lose their jobs and there are new upcoming events promising for the creation of new jobs. Job creation is one of the most important concerns in any society and it is a source of performance measurement for governmental organizations.

Many people use welfare to recover from the lack of financial support and, at the same time, they look for new job opportunities. In some cases, people may find it difficult to cope with new circumstances since they are under the impression that they are not entitled for any new opportunities. However, a simple consultation such as Bandura's social cognitive could change this attitude, significantly.

During the past decade, there have been tremendous efforts on using social cognitive questionnaires for measuring the impact of consultation. Schaub and Tokar (2005) investigated the role of

* Corresponding author. Tel.: +98 31136600 11; fax: +98 3517244084

E-mail addresses: sedrpoushan@iaukhsh.ac.ir (N. Sedrpoushan) 
personality and learning experiences in social cognitive career theory (SCCT). They extended the concept of SCCT by examining the posited indirect influence of personality on interests through learning experiences and sociocognitive effects, and by examining the hypotheses that self-efficacy percepts and outcome expectations are from corresponding career-relevant learning experiences. They selected 327 college students to complete a measure of the Big Five personality factors and measured of learning experiences, outcome expectations, self-efficacy and interests associated with each of six RIASEC themes. They reported that personality's relation to interests was mediated via learning experiences as well as sociocognitive mechanisms; but it was different considerably across the different personality-interest relations. Findings also revealed strong support, across Holland themes, for SCCT's hypothesize of self-efficacy and outcome expectations.

Chiu et al. (2006) integrated the social cognitive theory to build a framework for studying the motivations behind people's knowledge sharing in virtual communities. The results helped in describing the motivation underlying individuals' knowledge sharing behavior in professional virtual communities.

Wang and Wu (2008) explained that the social cognitive perspective of self-regulated learning could recommend that effective learning could be determined by the interactions among behavioral, personal and environmental effects; more specifically, high self-regulated learners hold higher personal motivation, use better learning behavioral strategies and respond to environmental demand more environmental, appropriately. The investigation implemented the social cognitive perspective to detect the role of personal self-efficacy, student feedback behavior, use of learning behavioral strategies, performance and receiving environmental feedback in Web-based learning. Their results showed that feedback behaviors had not predicted academic performance, which could be interfered by modeling influences.

Zikic and Saks (2009) used social cognitive theory could to explain the relationships between careerrelevant activities including environmental and self career exploration, career resources, and training, self-regulatory variables, which consist of job search self-efficacy and job search clarity), variables from the Theory of Planned Behavior, which are job search attitude, subjective norm, job search intention and job search intensity.

The results of the survey among employed and unemployed job seekers indicated that job seekers who spent more time in career exploration, participated in more training programs, and used more career resources reported higher job search clarity and job search self-efficacy. The results of this study suggested some guidelines on what job seekers could do to improve their job search clarity and job search self-efficacy and showed the application of social cognitive theory for learning more about job search behavior.

Lin and Bhattacherjee (2009) investigated the relationship between online social support and its antecedents through a socio-cognitive model. The study confirmed a research model, which investigated the above issue. They postulated self-efficacy and online support expectancy as the key components of information technology (IT) usage, whereas IT usage and referent network size jointly impact online social support in the setting of IT. The study contributed to the social science literature by extending IT usage models to the area of rarely explored online social support and by presenting an operationalization of referent network size in the area.

Lent et al. (2010) used a test of SCCT for predicting job interests among Portuguese high school students. They asked 600 participants to complete measures of occupational self-efficacy, interests, social supports outcome expectations and barriers, and choice consideration across the six RIASEC types. Contrary to SCCT, however, social supports and barriers associated with choice consideration indirectly, indirectly. 
Hawley et al. (2010) performed a social cognitive approach to tackle inactivity and obesity in young Australians. Tsai and Cheng (2010) examined programmer's perceptions of knowledge-sharing behavior under social cognitive theory. They examined key important factors, including self-efficacy, expectancy theory and organizational climate, on the software workers for sharing knowledge, using a social cognitive framework. They investigated programmers and software workers in Taiwan to examine the proposed research model. Confirmatory factor analysis as well as structural equation modeling technique was implemented to study the data and evaluate the research model. The results revealed that the research model fit the data well and the main determinants of knowledge-sharing behavior were the encouraging intentions of knowledge intensive workers. They also confirmed that that knowledge sharing self-efficacy and outcome expectancy, as well as organizational climate, influences individual intentions to share knowledge.

Thompson and Dahling (2012) investigated the social status and learning experiences in SCCT. They emphasized the relative importance of perceived social status as a predictor of exposure to different types of career-related learning experiences, which significantly influence students' self-efficacy, outcome expectations, and interests in particular RIASEC areas. The results were also investigated in terms of exposure to career-related learning experiences in RIASEC domains with various stages of prestige and implications of these results for developing interventions to enhance the learning experiences of those students who reported lower levels of perceived social. Thompson and Dahling (2012) evaluated the perceived social status and learning experiences in SCCT.

They showed perceived social status is associated positively with learning experiences in the Investigative, Enterprising, and Conventional areas among 380 university students. Further, these enhanced learning experiences explained the relationships between perceived social status and selfefficacy, and between perceived social status and outcome expectations. These findings highlighted the effects of perceived social status as a predictor of exposure to various types of career-related learning experiences, which subsequently shape students' self-efficacy, outcome expectations and RIASEC areas.

In this paper, we perform an empirical study among 280 welfare receivers to measure the effects of social cognitive consultation on changing receivers' entrepreneurship attitudes. The organization of this paper first presents details of the hypothesis in section 2 and section 3 presents the results of our survey. Finally, concluding remarks are given in the last to summarize the contribution of the paper.

\section{Proposed study}

In this study, we perform an empirical study among 280 welfare receivers to measure the effects of social cognitive consultation on changing receivers' entrepreneurship attitudes. Therefore, the following formula is sused to calculate the minimum number of sample size,

$n=\frac{N \times z_{\alpha / 2}^{2} \times p \times q}{\varepsilon^{2} \times(N-1)+z_{\alpha / 2}^{2} \times p \times q}$,

where $N$ is the population size, $p=1-q$ represents the yes/no categories, $z_{\alpha / 2}$ is CDF of normal distribution and finally $\varepsilon$ is the error term. Since we have $p=0.5, z_{\alpha / 2}=1.96$ and $N=280$, the number of sample size is calculated as $n=100$. All questions were desined in Likert scale (Likert, 1932) and distributed among volunteers.

The study uses Bandura's social cognitive questionnaire and select 30 out of 100 volunteers who receive the lowest marks in this survey and they are divided into two groups. The study provides a consultation among them for eight consecutive sessions of two hour-period. The intend of negotiation and consultation among one group was to examine whether we could change welfare recipients' characteristics. There are two hypotheses examined in our survey, which are as follows, 
H1: Social cognitive consultation will change welfare recipients' perception on entrepreneurship activities.

H2: Social cognitive consultation will change people's mind on welfare recipients' entrepreneurship behavior.

\section{Results}

As we explained earlier, we have divided the sample into two groups of 15 people, control and exam. For each hypothesis, we perform two tests on learning the effects of consultation before and after the eight sessions happen.

\subsection{First hypothesis}

Table 1 shows t-student results between two groups. In Table 1, we examine whether there is any difference between people's perceptions in two groups of control and exam.

\section{Table 1}

The results of t-student for the first hypotheses, the mean of difference of welfare recipients' perception towards entrepreneurship activities before consultation happens

\begin{tabular}{lcccccc}
\hline Group & Sample size & Mean & Standard deviation & t-student & p-value & degree of freedom \\
\hline Control & 15 & 262 & 56.46 & \multirow{2}{*}{1.002} & 0.315 & 28 \\
Exam & 15 & 242 & 49.33 & & \\
\hline
\end{tabular}

As we can observe from the results of Table 1, there is no meaningful difference between the two groups of control and exam, when the significance level is $\alpha=0.05$, while the consultation has not been established. Table 2 shows details of our survey after consultation happens.

\section{Table 2}

The results of t-student for the first hypotheses, the mean of difference of welfare recipients' perception towards entrepreneurship activities after consultation happens

\begin{tabular}{lclcccc}
\hline Group & Sample size & Mean & Standard deviation & t-student & p-value & degree of freedom \\
\hline Control & 15 & 240.86 & 36.29 & -11.39 & \multirow{2}{*}{0.022} & 28 \\
Exam & 15 & 456.86 & 63.83 & & \\
\hline
\end{tabular}

As we can see from the results of Table 2, there is a meaningful difference between the mean difference of welfare recipients' perception towards entrepreneurship activities right after the receive eight sessions of consultation when is the level of significance is $\alpha=0.05$. Therefore, we can conclude that consultation plays an important role on changing people's perception after the consultation happens.

\subsection{Second hypothesis}

The second hypothesis is associated with the relationship between social cognitive consultation and welfare receivers' entrepreneurship behavior and the results are summarized in Table 3.

\section{Table 3}

The summary of t-student for the second hypotheses, the mean of difference of welfare recipients' behavior towards entrepreneurship activities before consultation

\begin{tabular}{lcccccc}
\hline Group & Sample size & Mean & Standard deviation & t-student & p-value & degree of freedom \\
\hline Control & 15 & 31.60 & 4.25 & -0.132 & \multirow{2}{*}{0.07} & 198 \\
Exam & 15 & 31.86 & 6.53 & & \\
\hline
\end{tabular}


The results of Table 3 clearly show that there is no meaningful difference between the two groups of control and exam, when the level of significance is $\alpha=0.05$, while the consultation has not been established. Table 4 shows details of our survey after consultation happens.

\section{Table 4}

The summary of t-student for the second hypotheses, the mean of difference of welfare recipients' behavior towards entrepreneurship activities after consultation

\begin{tabular}{lcccccc}
\hline Group & Sample size & Mean & Standard deviation & t-student & p-value & degree of freedom \\
\hline Control & 15 & 24.33 & 4.38 & \multirow{2}{*}{12.25} & \multirow{2}{*}{0.006} & 28 \\
Exam & 15 & 40.13 & 2.38 & & \\
\hline
\end{tabular}

As we can see from the results of Table 4, there is a meaningful difference between the mean difference of welfare recipients' perception towards entrepreneurship activities right after the receive eight sessions of consultation when is the level of significance is $\alpha=0.05$. Therefore, we can conclude that consultation plays an important role on changing people's behavior after consultation happens.

In summary, we can conclude that it is possible to influence people's mind and perception to think differently in terms of job creation and contributing to society. The proposed study clearly explains that job creation can be promoted in societies should we create strong motivations among civilians.

\section{Conclusion}

In this study, we have performed an empirical study among 280 welfare receivers to measure the effects of social cognitive consultation on changing receivers' entrepreneurship attitudes. The study has used Bandura's social cognitive questionnaire and selected 30 volunteers who received the lowest marks from the questionnaires distributed in this survey. We divided these people into two groups. The study provides a consultation among them for eight consecutive sessions of two hour-period and the results indicated that the consultation could change both welfare receivers' perception and their attitude, significantly.

\section{Acknowledgment}

The authors would like to thank the officials of welfare organization of Semirom city in the province of Esfahan for their support in providing necessary assistance. This paper has been financially assisted by Islamic Azad University grant and the authors would like to thank the officials for their help.

\section{References}

Chiu, C. M., Hsu, M. H., \& Wang, E. T. G. (2006). Understanding knowledge sharing in virtual communities: An integration of social capital and social cognitive theories. Decision Support Systems, 42(3), 1872-1888.

Hawley, L., Harker, D., \& Harker, M. (2010). A social cognitive approach to tackle inactivity and obesity in young Australians. Journal of Business Research, 63(2), 116-120.

Lent, R.W., Paixão, M. P., da Silva, J. T., \& Leitão, L.M. (2010). Predicting occupational interests and choice aspirations in Portuguese high school students: A test of social cognitive career theory. Journal of Vocational Behavior, 76(2), 244-251.

Likert, R. (1932). A Technique for the Measurement of Attitudes. Archives of Psychology, 140, 1-55. 
Lin, C. P., \& Bhattacherjee, A. (2009). Understanding online social support and its antecedents: A socio-cognitive model. The Social Science Journal, 46(4), 724-737.

Schaub, M., \& Tokar, D.M. (2005). The role of personality and learning experiences in social cognitive career theory. Journal of Vocational Behavior, 66(2), 304-325.

Thompson, M.N., \& Dahling, J.J. (2012). Perceived social status and learning experiences in Social Cognitive Career Theory. Journal of Vocational Behavior, 80(2), 351-361.

Tsai, M.T., \& Cheng, N.C. (2010). Programmer perceptions of knowledge-sharing behavior under social cognitive theory. Expert Systems with Applications, 37(12), 8479-8485.

Wang, S.L., \& Wu, P.Y. (2008). The role of feedback and self-efficacy on web-based learning: The social cognitive perspective. Computers \& Education, 51(4), 1589-1598.

Zikic, J., \& Saks, A.M. (2009). Job search and social cognitive theory: The role of career-relevant activities. Journal of Vocational Behavior, 74(1), 117-127. 